\title{
Getting the timing right
}

\section{Elizabeth Loder, acting head of research}

\section{The BMJ}

I recall very few patients during my training years who survived an in-hospital cardiac arrest. Even fewer were discharged without some kind of neurological impairment. Resuscitation attempts - termed "codes" - were nonetheless prolonged and conducted according to elaborate guidelines. These specified the sequence and timing of various interventions such as medications and defibrillation attempts. Every few years, usually amid much controversy, the guidelines were updated and we adjusted the ritual.

Has anything improved? A 2012 analysis $^{1}$ showed that overall risk adjusted survival rates following in-hospital cardiac arrest increased from $13.7 \%$ in 2000 to $22.3 \%$ in 2009 . Rates of neurologic impairment declined. This is, depending on your point of view, bad or good news. The pace is slow, but movement is in the right direction.

Two papers in this issue of The BMJ delve deeper, examining the impact of specific changes in the timing of key resuscitation interventions for different types of cardiac arrest. The updated recommendations were issued in 2005 , so enough time has now elapsed to evaluate their effect.

Both studies show that adherence to guideline recommendations is modest, even in US hospitals participating in the Get with The Guidelines-Resuscitation registry.

Andersen and colleagues (doi:10.1136/bmj.i1577) found that about half of patients with a shockable rhythm received adrenaline sooner than recommended following defibrillation, and this early administration was associated with decreased odds of survival.
Similarly, Bradley and colleagues (doi:10.1136/bmj.i1653) found that a proper time interval occurred between defibrillation attempts in only $57 \%$ of patients with persistent ventricular fibrillation or pulseless ventricular tachycardia. Adherence to the recommended time interval between defibrillation attempts, however, was not associated with better survival outcomes.

Editorialists Couper and Perkins (doi:10.1136/bmj.i1858) say that this "widespread non-adherence to clinical guidelines" should promote soul searching and reform to ensure that resuscitation practices are "informed by the latest clinical guidelines." The figure that accompanies their commentary summarises the 2005 changes in the American Heart Association guidelines and is worth a look: a few well chosen symbols and numbers clearly convey the suggested order and schedule of resuscitation events.

Getting the timing right is a challenge with many other guideline recommended interventions. Melissa Whitworth (doi:10.1136/ bmj.i1655) notes that both WHO and NICE endorse the use of antenatal corticosteroids to reduce neonatal morbidity and mortality in premature babies, but accurate identification of true preterm labour is difficult. Timing matters, because maximum benefit occurs 1 to 7 days after these are administered to the mother.

1. Girotra S, Nallamothu BK, Spertus JA, Li Y, Krumholz HM, Chan PS. Trends in survival after in-hospital cardiac arrest. N Engl J Med 2012;367:1912-20doi:10.1056/ NEJMoa1109148.

Published by the BMJ Publishing Group Limited. For permission to use (where not already granted under a licence) please go to http://group.bmj.com/group/rights-licensing/ permissions 